\title{
DISCUSIONES
}

\section{VERIFICACIONISMO Y CLASES NATURALES EN EL ATAQUE CONTRA LA PRIVACIDAD}

\author{
ENRIQUE VILLANUEVA \\ Universidad Nacional \\ Autónoma de México
}

En un volumen reciente sobre filosofía de la mente ${ }^{1}$ se abordan dos aspectos muy importantes en el argumento que se atribuye a Wittgenstein contra el lenguaje privado. En publicaciones anteriores ${ }^{2}$ me había ocupado de estos tópicos en forma somera. Ahora quiero comentarlos específicamente a propósito de las contribuciones de J. S. Clegg y Charles E. Marks.

Un cargo usual en contra del argumento del lenguaje privado es el de que ese argumento emplea una premisa verificacionista. ${ }^{3}$ En su contribución "Wittgenstein on Verification and Private Languages", J. S. Clegg ataca con arrojo esa

1 New Essays in the Philosophy of Mind (Guelph, Ontario: Canadian Journal of Philosophy Supplementary, Volume No. 1, 1975). El volumen contiene otras contribuciones importantes, a saber, "Observation and Subjectivity in Quine" por Harold Morick; dos artículos sobre filosofía de la acción: "Actions" por L. H. Davis y "Can Desires be Causes of Actions?" por T. A. Browne; uno sobre Strawson: "Strawson's Transcendental Deduction of Other Minds" por J. L. Marin; y dos sobre el problema de la mente y el cuerpo: "Physicalism and the Evolution of Consciousness" por Roland Puccetti y "Scientific Reduction and the Mind-Body Problem" por L. F. Mucciolo.

2 Véanse los artículos "El argumento del lenguaje privado I" en Crítica, VII, 20, octubre 1975, y "El argumento del lenguaje privado II", en Crítica, VII, 21, diciembre 1975.

3 Un defecto importante de la exposición y objeción de Clegg es el de que no especifica el cargo de verificacionismo. Otro defecto grave es que trata de salvar la objeción en base a la coherencia del pensamiento de Wittgenstein; esto es deplorable desde el punto de vista del avance filosófico.

Respecto a lo primero, verificacionismo en el sentido de un criterio para eliminar los enunciados no-científicos no es lo que se argumenta. Más bien parece tratarse de una condición suficiente de la significatividad de los enun. ciados; sin embargo, se confunde este intento con otro más plausible, a saber, el de que la significación de una proposición está intimamente conectada con el valor de verdad de la misma (no con los procedimientos u operaciones 
objeción. Según Clegg, Wittgenstein nunca sostuvo un verificacionismo; por el contrario, su doctrina de las auto-atribuciones de sensación niega que éstas sean verdaderas o falsas qua auto-atribuciones. ¿Por qué suponer que Wittgenstein le exige al putativo diarista privado lo que no exige al hombre común que se auto-atribuye, v.gr. un dolor? Clegg rechaza la posibilidad de que las Investigaciones Filosóficas conten. gan este tipo de confusión y decide tomar un camino atrevido en la interpretación del argumento del lenguaje privado. Según Clegg, la putativa persona que lleva un diario privado no puede realizar pruebas o verificaciones de sus propias sensaciones de la misma manera que un hombre no puede prestarse dinero a sí mismo. En el primer caso, las "pruebas" que quiere llevar a cabo no tienen ninguna consecuencia y por ello no prueban nada; de igual manera, no cabría esperar que uno se demandara judicialmente por no haber devuelto el dinero del imaginable auto-préstamo.

Clegg concluye en que ni la verificación ni la decisión de si algo es verdadero o falso le son esenciales al lenguaje, pero esto es demasiado. Uno puede rechazar lo primero -hasta cierto punto- pero no lo segundo; además, es innecesario hacerlo. De otra parte, ¿qué hacer con las autoatribuciones? Uno mismo no las verifica pero otros lo hacen. He aquí una sugerencia mía: las auto-ascripciones no son ni verdaderas ni falsas según el modelo nominativo de la significación y uno mismo no las verifica, pero son verdaderas y falsas y también verificables cuando se las usa en conjunción con las atribuciones a otras personas y a las cosas materiales. Esta sugerencia explica dos perplejidades que surgen en el argumento del lenguaje privado, a saber, que no puede haber nombres privados y que los signos privados pueden llegar a ser nombres sólo cuando entran en conexión con el

que se requieren para establecer ese valor de verdad). Si a esto último se le quiere llamar verificaciones, habrá que presentar argumentos muy fuertes para demostrarlo falso. Pero, repito, los que hacen el cargo de verificacionismo no aclaran suficientemente el problema y lo que envuelve. 
lenguaje público, esto es, con el lenguaje de otras personas y de los objetos materiales.

Esta sugerencia mía puede atemperar la forma avezada que adquiere la defensa de Clegg al tiempo que evita una perplejidad innecesaria.

Hasta la fecha no hay una explicación satisfactoria de qué tipo de verificacionismo asume una premisa del argumento contra el lenguaje privado ni tampoco de cuán dañina sea esa asunción. Sin embargo, muchos autores se escandalizan al oír hablar de verificacionismo y piensan que es mejor abandonar el citado argumento. Charles E. Marks, en "Can One Recognize Kinds of Private Objects?", toma ese camino parcialmente. Según Marks hay una tradición que asume verificacionismo y escepticismo de la memoria para establecer que no es posible un lenguaje privado. Esto es implausible e innecesario, piensa Marks; hay un punto anterior a estos que permite establecer la imposibilidad de un lenguaje privado, a saber, que no puede haber un lenguaje privado porque no puede haber nombres privados y esto a su vez porque no puede haber clases de objetos privados. Veamos.

Marks piensa que quien introduce la idea de un lenguaje privado y su idea correspondiente de objetos privados piensa que basta su afirmación para que esos objetos queden establecidos. Pero no basta con declarar esa intuición (si es que hay tal intuición) porque esto es demasiado fácil. Si se le va a dar algún peso a "objeto" en "objeto privado" hay que suponer que esos objetos forman clases naturales que permiten inducciones, descripciones, predicciones y en fin, comprensión de ese universo privado. Sin este mínimo, la idea de un lenguaje privado resulta algo gratuito e indigno de consideración. Así Marks alimenta la hipótesis del lenguaje privado con la idea de putativas clases naturales de objetos privados.

Basándose en una sugerencia de Wittgenstein, Marks em. plea dos argumentos en contra de tales clases naturales privadas. El primero es uno en que la persona privada cree 
que un conjunto de objetos no ligados entre sí son similares y forman una clase, pero esta persona no es capaz de distinguir este juicio de similaridad cuando en otra ocasión juzga que otros objetos arbitrariamente seleccionados son los que forman la clase en cuestión, porque su sentido de similaridad se alteró concomitantemente a la alteración en la composición de la clase.

En el segundo argumento los objetos están ligados por relaciones de tipo legal [law-like] pero los juicios del sujeto privado escogen arbitrariamente las clases de objetos así regulados con resultados igualmente desastrosos.

¿Cómo eliminar la arbitrariedad? Marks apunta rápidamente a una posible conexión de los objetos privados con los objetos públicos. Esto ciertamente eliminaría la arbitrariedad al seleccionar clases de objetos pero sólo al precio de perder la privacidad.

Aquí el defensor de las clases naturales de objetos privados puede argumentar que las objeciones de Marks sólo prueban que uno no puede ni dar una descripción de esas clases privadas ni explicar cómo sabe que se reconoce una clase como privada que no sea auto-destructiva, pero no prueba que no haya clases privadas $y^{\prime}$ que la persona privada las identifique. Marks replica diciendo que si hay tales clases y tal reconocimiento es necesario que haya descripciones e inducciones que expliquen $y$ justifiquen su existencia; de otro modo sólo se ofrece una afirmación vacía, según se apuntó al principio. Por ello es que al mostrar que no puede haber predicciones ni inducciones consistentes porque las putativas clases de objetos privados son arbitrarias y lo son igualmente los juicios sobre ellas, se muestra que hablar de "clases de objetos privados" es sólo bluff.

$\mathrm{El}$ argumento de Marks es novedoso e imaginativo, pero parece suponer que no se puede ofrecer una vía de acceso al objeto privado que no sea la vía epistemológica del que tiene ese objeto, es decir, parece que supone que solamente la persona privada tiene acceso a esos objetos y que sólo sus 
juicios pueden establecer una conexión (sistemática), entre la ocurrencia de objetos privados y los objetos o eventos públicos. Esta suposición no es verdadera a priori ni necesariamente. Marks concede además que no tiene un argumento contra esa posibilidad pero piensa que tampoco se ha mostrado ningún caso; mientras eso sucede la hipótesis de Marks, en el sentido de que los juicios de la putativa persona privada no pueden conectar los objetos privados con algo público de manera de decidir cuáles objetos privados forman una clase privada y cuáles no la forman, puede mantenerse; y si alguien presentase un contraejemplo, Marks debería mostrar cómo en base a esas conexiones puede romper la arbitrariedad que aqueja a las clases de objetos privados.

¿Pero qué es un objeto privado? Bueno, de acuerdo a Marks un objeto privado es, por ejemplo, una sensación de dolor cuando (1) se dice de ella que necesariamente sólo la persona que la tiene sabe que la tiene y sólo ella sabe cómo es (qué característica tiene) la sensación y por consecuencia, (2) nadie aparte de esa persona puede entender el nombre que da a la sensación en cuestión.

El segundo requisito me parece que da lugar a confusión porque parece que concede que hay nombres privados cuando se trata de decidir si puede haberlos y por lo tanto si puede haber un lenguaje que sea privado. Por otra parte, el defensor del lenguaje privado probablemente piense que lo importante es que hay objetos privados y que la conciencia registra su existencia, la clase a la que pertenecen, etc.

Más importante aún es el hecho de que Marks, al poner el argumento del lenguaje privado en términos de si puede haber clases de objetos privados, se expone a una gran variedad de objeciones. Entre ellas destaca una que es decisiva, a saber, que la mayoría de filósofos cartesianos de Descartes a Russell y Ayer no aceptaría la idea de objeto interno o privado. Lo que es peor, no se ve la forma en que podrían reducirse las afirmaciones de esos filósofos a la idea de 
objeto interno. Mientras Marks no muestre esto, no habrá dado peso a su argumento.

Otra objeción - y con ésta concluyo- es que la ventaja que Marks alega en su favor de que su argumento no implica ni verificacionismo ni escepticismo en la memoria, podría recibir la respuesta de que sí implica algo parecido a esos cargos. Implica "verificacionismo" porque trata de decidir cuáles clases de objetos son correctas y cuáles no lo son e implica escepticismo porque supone que o bien los objetos acaecen irregularmente o los juicios de la putativa persona privada no son correctos. Ambas objeciones son nebulosas, pero Marks no provee mayor esclarecimiento.

Es interesante observar que argumentos como el del lenguaje privado o el de la traducción radical atraen más y más el interés de los filósofos aun cuando quedan muy lejos del esclarecimiento fundamental que prometen. Puesto que ello es así, cabe pensar que el interés que esos argumentos despiertan hablan más del carácter de los propios filósofos que de lo que es posible hacer en filosofía. 